\title{
Achromobacter xylosoxidans
}

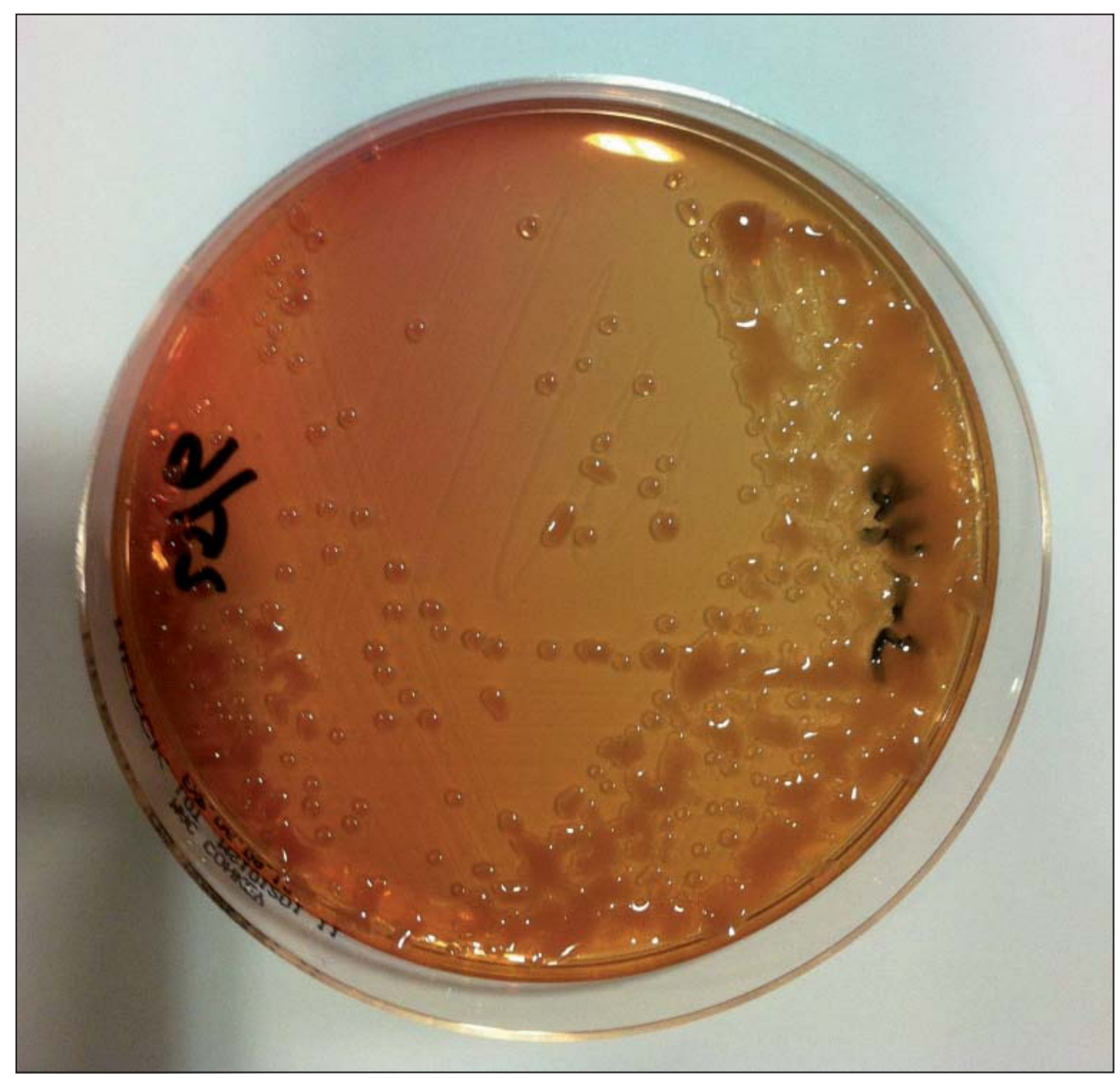

Figura 1. Cultivo de Achromobacter xylosoxidans a las 48 h de incubación en agar Mac Conkey. 


\section{Retrato Microbiológico}

\section{Achromobacter xylosoxidans}

Agente descrito en 1971, también conocido como Alcaligenes denitrificans subsp xylosoxydans. Se ha aislado en muestras de piel, orina, sangre, tracto respiratorio, LCR, líquido peritoneal y abcesos, entre otras. El significado clínico del agente es difícil de determinar. Ha sido descrito como agente oportunista en pacientes hospitalizados, con disminución en los mecanismos de defensa y sometidos a procedimientos invasores. También se ha descrito en brotes, aislándose en clorhexidina y otros elementos de uso hospitalario. Es un agente frecuente en ambientes húmedos. Su fuente principal es el agua (piscinas, líquido de diálisis, agua destilada y desionizada, agua potable y de pozo, soluciones desinfectantes y medicamentos en ampollas). Se le ha descrito también como patógeno en pacientes con fibrosis quística, afectando a $9-10 \%$ de ellos. Suele confundirse con el complejo Burkholderia cepacia. En general, este agente es considerado de baja virulencia, pero la mortalidad varía según el hospedero, desde 30 hasta $80 \%$ en neonatos.

Este bacilo gramnegativo no fermentador puede observarse aislado o en diplo y con flagelos peritricos. Es aerobio obligado, de colonia pequeña de $0,75 \mathrm{~mm}$ de diámetro, translúcida, brillante, convexa, con coloración grisácea, no hemolítica y mucosa. A las $48 \mathrm{hrs}$, las colonias pueden tener un tamaño de $4 \mathrm{~mm}$, ser extremadamente mucosas y presentar una pequeña $\beta$-hemólisis. Crece en agar Mac Conkey, es lactosa negativa, oxidasa positiva, citrato y catalasa positivos, móvil y reduce nitrato. Oxida la xilosa y glucosa en forma muy lenta y no otros carbohidratos. Es arginina, lisina decarboxilasa, ornitina, gelatina, indol, Voges Proskauer, ureasa y ADNasa negativas.

Para su identificación se utilizan los métodos microbiológicos clásicos o sistemas comerciales tipo APIß, automatizados y métodos moleculares.

En general, es resistente a $\beta$-lactámicos, aminoglucósidos, cefalosporinas de primera y segunda generación y quinolonas. Sensible a ceftazidima, colistín, carbenicilina, piperacilina/tazobactam, imipenem, meropenem, cotrimoxazol y cloranfenicol. Los métodos estandarizados para su estudio in vitro corresponden al CLSI M100 -S22 en la sección "otros no enterobacteriaceas", que sólo contiene criterios interpretativos para CIM.

Andrea Sakurada

Comité de Microbiología Sochinf Laboratorio de Microbiología Clínica Tabancura.

Correspondencia a:

Andrea Sakurada Z.

andreasakurada@gmail.com

Una versión in extenso de este Retrato Microbiológico puede encontrarse en www.sochinf.cl 